\title{
Effect of danazol on the biochemical abnormality of inherited antithrombin III deficiency
}

\author{
AJ FAIRFAX, RM IBBOTSON \\ From the Department of Thoracic Medicine, Staffordshire General Infirmary, Stafford, and the Department of \\ Haematology, Central Pathology Laboratory, Hartshill, Stoke on Trent
}

ABSTRACT Seven members of a family affected by hereditary antithrombin III deficiency were identified. The disorder was associated with recurrent spontaneous episodes of phlebitis, deep venous thrombosis, and pulmonary embolism in middle age. Danazol, a 17-alkyl derivative of ethinyl testosterone, which has been used to treat other antiprotease deficiency states, was assessed in the management of two men with antithrombin deficiency. In a dose of $600 \mathrm{mg}$ a day danazol appeared to correct the antithrombin deficiency. This drug may provide a useful adjunct to anticoagulant treatment, particularly before surgery.

Inherited antithrombin III deficiency (hereditary thrombophilia) is a rare disorder, first described by Egeberg in $1965,{ }^{\prime}$ which is characterised by recurrent, sometimes fatal, deep vein thrombosis and pulmonary embolism. When recognised, the condition is usually treated by long term anticoagulation. The control mechanisms that inhibit blood coagulation are vital for homeostasis. The activation sequence in the coagulation cascade contains negative feedback effects that tend to limit thrombin formation.

Antithrombin is one of the protease inhibitors present in blood and its main role is to inactivate thrombin. Antithrombin also inactivates all the clotting enzymes except factor VIIa. Heparin accelerates the reaction between antithrombin and the clotting enzymes.

The structure of antithrombin has recently been determined and is very similar to that of $\alpha_{1}$ antitryp$\sin .^{2}$ They are believed to have evolved from a common ancestral protein-a mutation resulting in the substitution of a single amino acid (arginine for methionine) in the $\alpha_{1}$ antitrypsin molecule converts this from an inhibitor of elastase to an inhibitor of thrombin. ${ }^{3}$ Molecular heterogeneity occurs in inherited antithrombin III deficiency as in $\alpha_{1}$ antitrypsin deficiency. ${ }^{4}$

Address for reprint requests: Dr AJ Fairfax, Department of Thoracic Medicine, Staffordshire General Infirmary, Stafford ST16 2PA.

Accepted 29 March 1985
Synthetic androgens such as danazol are known to induce the formation and release of various protease inhibitors, including $\mathrm{Cl}$-esterase inhibitors and $\alpha_{1}$ antitrypsin. ${ }^{6}$ The mechanism underlying this effect is unknown. The aim of this study was to determine whether danazol would correct the biochemical abnormality in inherited antithrombin III deficiency.

\section{Methods}

ANTITHROMBIN III ASSAY

Blood was mixed with citrate anticoagulant $(3.8 \%$ trisodium citrate 1 vol: 9 vol blood). After centrifugation the separated plasma was stored at $-70^{\circ} \mathrm{C}$. Antithrombin III antigen was measured by radial immunodiffusion,? Behringwerke Norpartigen plates being used (Behringwerke AG, Marburg, West Germany). Biological antithrombin III activity was assessed as heparin cofactor with chromogenic substrate S 2238 (Coa test, Kabi AB, Stockholm). This functional assay using a synthetic chromogenic substrate has been shown to give a sensitive and precise measure of antithrombin activity in plasma. ${ }^{8}$ The laboratory normal ranges for functional antithrombin III and antithrombin III antigen are $84-116 \%$ and $72-128 \%$. The results are conventionally expressed as percentages of the activity present in reference plasma. The Coa test for functional antithrombin III activity has a coefficient of variation of $2.1(\mathrm{n}=35)$ and the radial immunodiffusion method a coefficient of variation of $2.3(n=14)$. Warfarin anticoagulant control was monitored with the Manchester comparative 


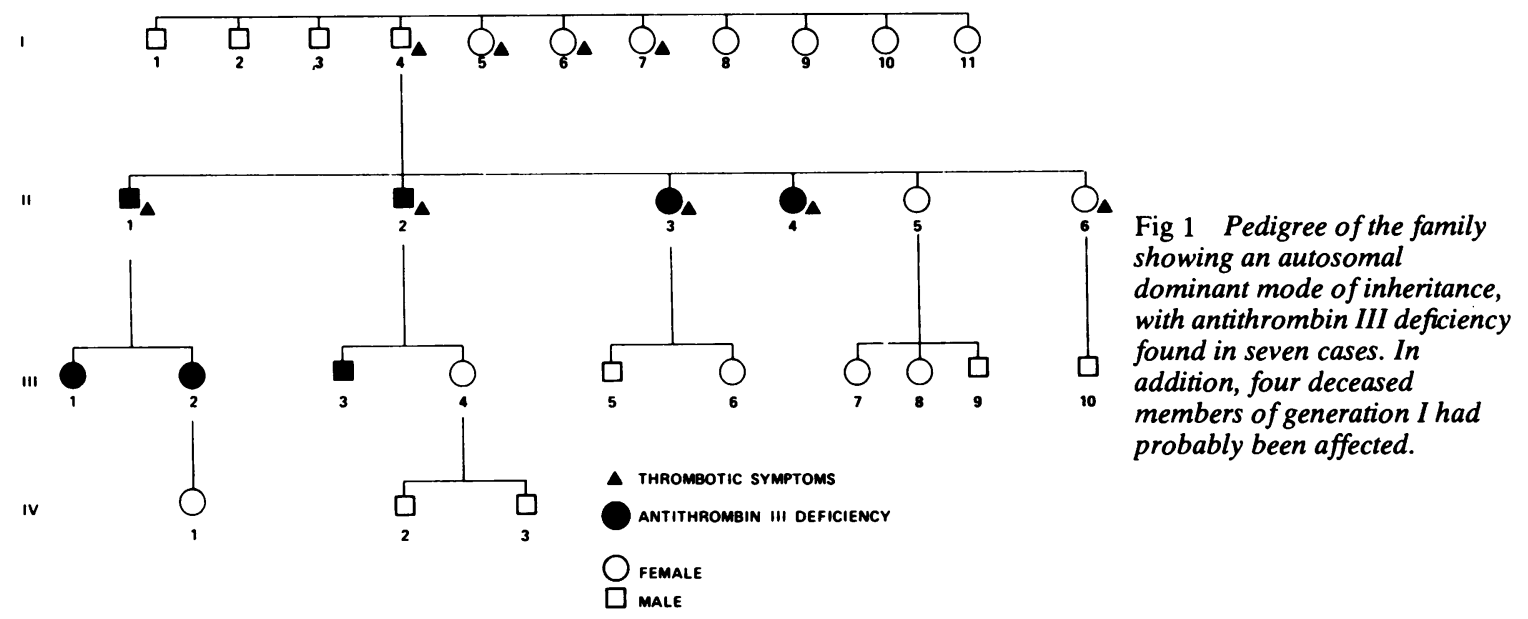

reagent and adjusted to the therapeutic range 1.8-3.0.

\section{Case reports and results}

The generations of the affected family are shown in figure 1, designated by Roman numerals.

\section{THE CASES}

Case II 1 The index patient, a 56 year old farmer, was well until the age of 41 , when he developed pain and stiffness in the left leg. One year later. he became breathless and experienced bilateral pleuritic pain. Investigations showed multiple pulmonary emboli associated with small pleural effusions. He was treated with warfarin for seven months. He remained well for 10 years and then had a spontaneous right deep venous thrombosis, confirmed by venography. Warfarin was given for eight months and he was then prescribed long term aspirin treatment. Two years later, when he was 54 , his left leg swelled intermittently and he experienced further pleuritic pain. Multiple pulmonary emboli were demonstrated on a perfusion lung scan. These subsequently resolved. Antithrombin III deficiency was diagnosed and he was given long term anticoagulation treatment with warfarin. Currently he complains of intermittent aching in the left calf, varicose eczema, and varicose veins. His father had symptoms from leg veins and a familial tendency to phlebitis had been recognised by the family. Other members of the preceding generation (I) had had symptoms suggesting antithrombin deficiency but were now dead (fig 1).

Case II 2 A 59 year old farmer, brother of the propositus, presented at the age of 48 with pleuritic pain and a swollen right calf. One month later the left calf also became swollen and venography showed a deep venous thrombosis. He was treated for seven months with warfarin, but when this was discontinued the leg symptoms recurred. He was subsequently treated with warfarin indefinitely. He was found to have hyperlipidaemia at the age of 51 and was started on a low cholesterol diet and clofibrate. A further episode of suspected pulmonary embolism occurred when he was 55 . He suffered two myocardial infarctions at the age of 57 and again two years later. The right leg swells intermittently and there are visible varicose veins and varicose eczema.

Other family members The siblings in generation II were all traced and three had varicose veins or thrombotic symptoms or both. Two of these (II 3 and II 4) were found to have antithrombin III deficiency. All those with either deep venous thrombosis or pulmonary embolism had developed their first symptoms after the age of 40 years. All the offspring from the affected individuals in generation II were examined except for one who had died in an accident. Three of the 10 who were seen in this generation (III) also had antithrombin III deficiency; two of them (aged 23 and 25) were symptomless and one had varicose veins (fig 1 ).

\section{RESULTS OF INVESTIGATIONS}

In the seven affected family members the functional assay gave values of $33-69 \%$ for antithrombin III activity (normal range $84-116 \%$ ) with a mean (SD) value of $56 \%(11 \%)$. The immunoassay results were usually slightly higher, with a mean (SD) of $66 \%$ 
Family members with antithrombin III deficiency

\begin{tabular}{|c|c|c|c|c|c|c|}
\hline \multirow[t]{2}{*}{ No } & \multirow[t]{2}{*}{ Sex } & \multirow[t]{2}{*}{ Age (y) } & \multirow[t]{2}{*}{ Clinical features } & \multicolumn{2}{|c|}{ Antithrombin activity (\%) } & \multirow[t]{2}{*}{ Treatment } \\
\hline & & & & Chromogenic & Antigenic & \\
\hline II 1 & $\mathbf{M}$ & 56 & $\begin{array}{l}\text { Recurrent DVT, } \\
\text { pulmonary embolism, } \\
\text { varicose veins }\end{array}$ & $33-75$ & $56-68$ & Warfarin \\
\hline II 2 & $\mathbf{M}$ & 59 & $\begin{array}{l}\text { Recurrent DVT, } \\
\text { pulmonary embolism, } \\
\text { varicose veins, } \\
\text { coronary thrombosis }\end{array}$ & $36-57$ & $54-62$ & Warfarin \\
\hline II 3 & $\mathbf{F}$ & 63 & Recurrent DVT & $53-69$ & 68 & Warfarin \\
\hline II 4 & $\mathbf{F}$ & 48 & $\begin{array}{l}\text { Recurrent phlebitis, } \\
\text { varicose veins }\end{array}$ & $54-68$ & $65-66$ & \\
\hline III 1 & $\mathbf{F}$ & 27 & Varicose veins & $66-76$ & $78-102$ & \\
\hline III 2 & $\mathbf{F}$ & 25 & None & $37-40$ & $43-65$ & \\
\hline III 3 & $\mathbf{M}$ & 23 & None & 58 & 60 & \\
\hline
\end{tabular}

DVT-deep vein thrombosis.

(11\%), the normal range being $72-128 \%$ (table). The levels of functional antithrombin III activity showed a clear separation between affected and normal family members, the latter having values of 96-147\% (mean $122 \%$ ), with similar values of 90 $110 \%$ (mean $101 \%$ ) estimated by immunoassay. A raised serum cholesterol concentration of 7.4-9.2 $\mathrm{mmol} / \mathrm{l}(285.7-355.2 \mathrm{mg} / 100 \mathrm{ml}$ ) (normal range 4.0-6.5 mmol/l (154.4-251.0)) was found in four subjects with antithrombin III deficiency; two of these also had fasting hypertriglyceridaemia, with triglyceride concentrations of $3.5-5.3 \mathrm{mmol} / \mathrm{l}$ (309.7-469.0 $\mathrm{mg} / 100 \mathrm{ml}$ ) (normal range $0.5-2.0$ $\mathrm{mmol} / \mathrm{l}(44.2-177.0 \mathrm{mg} / 100 \mathrm{ml}))$.

\section{TREATMENT}

With informed consent, patients II 1 and II 2 were treated with danazol in divided doses by mouth of up to $600 \mathrm{mg} /$ day. This resulted in a rise in plasma antithrombin III activity within seven days of starting treatment as assessed by both assays (figs 2 and 3 ). No changes occurred in blood urea or electrolyte concentrations or in the results of liver function tests (including total protein and albumin), but the $\alpha_{1}$ antitrypsin activity increased during the periods of danazol treatment. Patient II 1 received two courses of danazol. The daily dose was progressively increased: $400 \mathrm{mg} /$ day was sufficient to bring the chromogenically assayed antithrombin III within the normal range (fig 3) and $600 \mathrm{mg} /$ day resulted in a further increase. The only side effects reported were mild headaches in one man and a sene of wellbeing in the other. Warfarin, which is known not to affect antithrombin III levels, ${ }^{9}$ was continued during the danazol treatment to keep the prothrombin ratio within the therapeutic range. The dose of warfarin had to be reduced in both cases to prevent excessive anticoagulation.

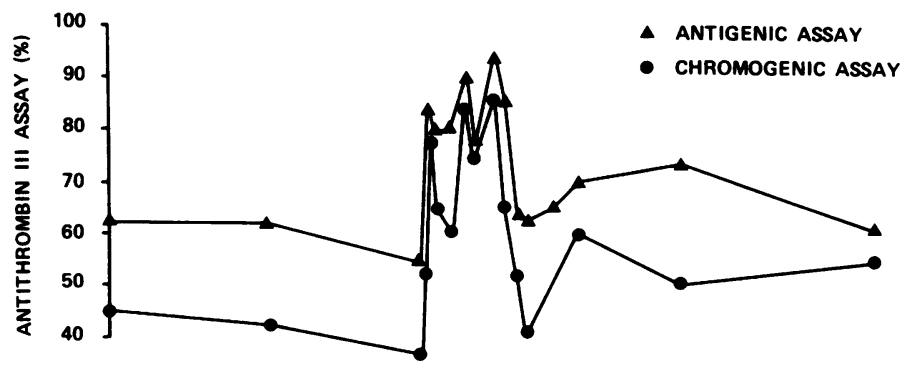

Fig 2 Response of antithrombin III level to danazol treatment (patient II 2).

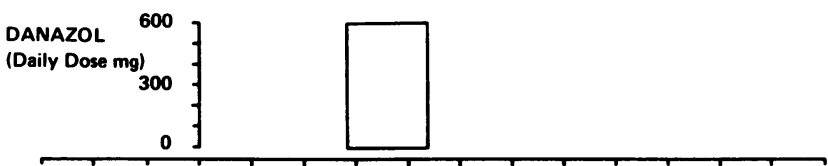



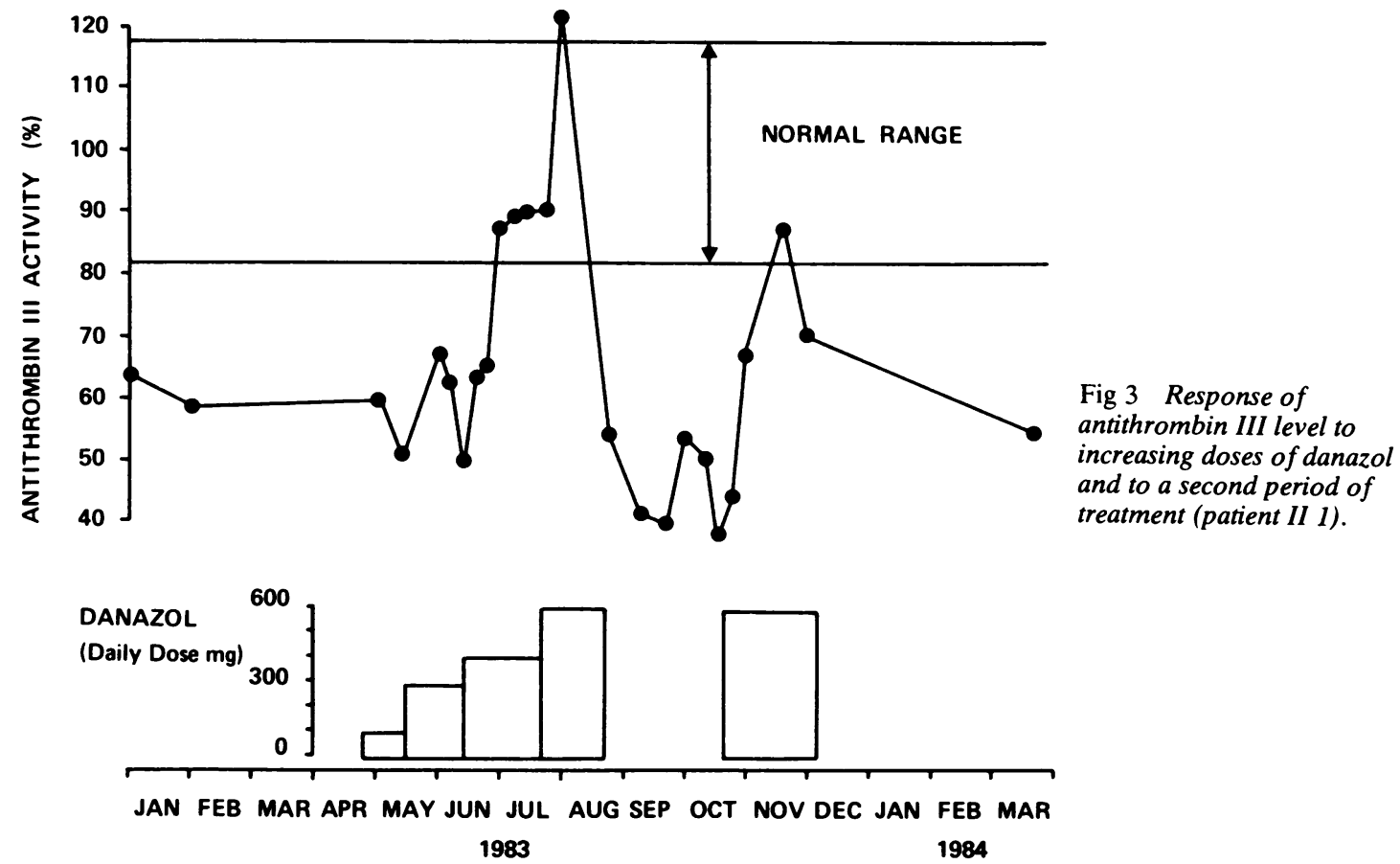

\section{Discussion}

The cases in this family are similar to those in other families with hereditary antithrombin III deficiency. ${ }^{9}$ The mode of inheritance is typically autosomal dominant as in this family. Recurrent deep venous thrombosis and pulmonary embolism later in life are characteristic of the condition. Varicose veins, probably secondary to previous deep venous thrombosis, were found in most of the affected members of this family, who had themselves recognised this to be a familial characteristic. Hyperlipidaemia may occur with antithrombin III deficiency but recent evidence suggests that this is a chance association. ${ }^{910}$

Anabolic steroids have previously been observed to produce a modest augmentation of plasma antithrombin III activity, ${ }^{1-13}$ in contrast to oestrogenprogesterone contraceptive preparations, which slightly depress antithrombin III activity. ${ }^{14}$ We are not aware of any previous reports of danazol in the treatment of antithrombin III deficiency, despite the drug's usefulness in other protease deficiency states and the recent interest in the possible use of danazol to augment factor VIII and factor IX activity in haemophilia and Christmas disease. ${ }^{15}$ In the two patients described a therapeutic dose of danazol reversibly corrected the antithrombin III deficiency without appreciable side effects. Alpha ${ }_{1}$ antitrypsin activity also increased, which is of interest in view of its very close molecular similarity to antithrombin III. ${ }^{2}$ In the present study danazol produced normalisation of antithrombin levels, in contrast with the modest changes reported with other drugs. ${ }^{11-13}$

For long term treatment warfarin is probably the treatment of choice. Danazol offers a possible alternative where warfarin is sometimes contraindicated-for example, before major surgery. The drug may also prove a useful adjuvant to anticoagulation where venous thrombosis occurs despite warfarin treatment.

We wish to thank Mrs L Ollerenshaw for her technical assistance.

\section{References}

1 Egeberg $O$. Inherited antithrombin deficiency causing thrombophilia. Thrombosis et Diathesis Haemorrhagica $1965 ; 13: 516-30$.

2 Carrell RW, Jeppsson JO, Laurell CB, et al. Structure and variation of human $\alpha_{1}$-antitrypsin. Nature 1982;298:329-34.

3 Owen MC, Brennan SO, Lewis JH, Carrell RW. Muta- 
tion of antitrypsin to antithrombin. $\alpha_{1}$-antitrypsin Pittsburgh (358 Met-Arg), a fatal bleeding disorder. $N$ Engl J Med 1983;309:694-8.

4 Prochownik EV, Antonarakis S, Bauer KA, Rosenberg RD, Fearon ER, Orkin SH. Molecular heterogeneity of inherited antithrombin III deficiency. N Engl J Med 1983;308:1549-52.

5 Gelfand JA, Sherins RJ, Alling DW, Frank MA. Treatment of hereditary angioedema with danazol. Reversal of clinical and biochemical abnormalities. $N$ Engl J Med 1976;295:1444-8.

6 Gadek JE, Fulmer JD, Gelfand JA, Frank MM, Petty TL, Crystal RG. Danazol-induced augmentation of serum $\alpha_{1}$-antitrypsin levels in individuals with marked deficiency of this antiprotease. J Clin Invest 1980;66:82-7.

7 Mancini G, Carbonara AO, Heremans JF. Immunochemical quantitation of antigens by single radial immunodiffusion. Immunochemistry 1965;2: 235-40.

8 Odegard OR, Lie M, Abildgaard U. Heparin cofactor activity measured with an amidolytic method. Thromb Res 1975;6:287-94.
9 Winter JH, Fenech A, Ridley W, et al. Familial antithrombin III deficiency. $Q J$ Med 1982;51:373-95.

10 Gyde OHB, Middleton MD, Vaughan GR, Fletcher DJ. Antithrombin III deficiency, hypertriglyceridaemia, and venous thromboses. $\mathrm{Br}$ Med J 1978;i:621-2.

11 Walker ID, Davidson JF, Young P, Conkie JA. Effect of anabolic steroids on plasma antithrombin III, $\alpha_{2}$ macroglobulin and $\alpha_{1}$-antitrypsin levels. Thrombosis et Diathesis Haemorrhagica 1975;34:106-14.

12 Fiessinger JN, Aiach M. Stanozolol treatment in an ATIII deficient patient. Thromb Haemostas 1980; 43:183.

13 Winter JH, Fenech A, Bennett B, Douglas AS. Prophylactic antithrombotic therapy with stanozolol in patients with familial antithrombin III deficiency. $\mathrm{Br} J$ Haematol 1984;57:527-37.

14 Fagerhol MK, Abildgaard U, Bergsjo P, Jacobsen JH. Oral contraceptives and low antithrombin-III concentration. Lancet 1970; i: 1175.

15 Gralnick HR, Rick ME. Danazol increases factor VIII and factor IX in classic hemophilia and Christmas disease. N Engl J Med 1983;308:1393-5. 